\title{
Antioxidative and Anti-Aging Effects of Pinus Rigida Mill. Ethyl Acetate Extract on the Human Dermal Fibroblast Cell Line CCD-986sk Damaged by Ultraviolet B Radiation
}

\author{
Young Ah Jang ${ }^{1}$, Bo Ae $\mathrm{Kim}^{2}$ and Jin Tae Lee*3 \\ ${ }^{1}$ Gennolab Co., LTD. Gyeongbuk 38540, Republic of Korea \\ ${ }^{2}$ College of Sciences \& Technology, Division of Biomedical \& Cosmetics, Mokwon University, Daejeon 302-729, Korea
}

${ }^{3}$ Department of Cosmeceutical Science, Daegu Haany University, Gyeongbuk 38540, Republic of Korea

Received: 制: December 12, 2018; Published: 制: January 02, 2019

*Corresponding author: Jin Tae Lee, Department of Cosmeceutical Science, Republic of Korea

\begin{abstract}
We analyzed the antioxidant and anti-wrinkle effects of Pinus rigida Mill. (pitch pine) to evaluate its use as a cosmetic material. 3-[4,5-Dimethylthiazol-2-yl]-2,5-diphenyl-tetrazoliumbromide assay was performed to evaluate the toxicity of the sample. To evaluate the antiwrinkle activity of P. rigida Mill., the amount of type I procollagen and TIMP-1 synthesized was measured, and Western blot analysis and RT-PCR were performed to determine the expression levels of wrinkle-related proteins and genes. To investigate the inhibitory effect of ROS of P. rigida Mill, we conducted experiments to induce oxidative damage by UVB radiation using zebrafish embryos. Cytotoxicity to EtOAc extract (PRE) was measured using the human dermal fibroblast cell line CCD-986sk, and cytotoxicity was not observed below the concentration of $20 \mu \mathrm{g} / \mathrm{mL}$. PRE has been shown to increase type I procollagen synthesis and promote the expression of its regulator, TIMP-1. In addition, P. rigida Mill. reduced the expression of MMP-1, -2, and -3 in CCD-986sk cells stimulated with UVB among the matrix metalloproteinases found in the dermal layers, which cause collagen reduction. After treatment with P. rigida Mill. extract at various concentrations, fluorescence spectra of ROS levels in the zebrafish embryos induced by UVB showed that fluorescence intensity decreased in a concentration-dependent manner compared with the intensity of the positive control group. Based on these findings, it is considered that $P$. rigida Mill. has value as a cosmetic material for antioxidant and anti-wrinkle benefits.
\end{abstract}

Keywords: Matrix Metalloproteinases; Pinus Rigida Mill; Photo Aging; Reactive Oxygen Species; Zebra Fish

\section{Introduction}

Based on the characteristics of aging, it can be divided into endogenous and exogenous aging. Endogenous aging is caused by cell and tissue damage over time, abnormal immune function, and imbalance of epidermal homeostasis, whereas exogenous aging is caused by ultraviolet (UV) radiation, free radicals, toxicity, allergens, and physical stimuli [1]. A typical risk factor for exogenous aging is UVB, and constant exposure of the skin to it triggers fibroblasts to produce reactive oxygen species (ROS), including superoxide anion, peroxides, and singlet oxygen, which are considered harmful to humans. This reaction causes structural changes in the extracellular matrix, such as changes in collagen, elastin, proteoglycan, and fibronectin [2, 3]. Excessively produced ROS can trigger DNA denaturation, which causes mutations in elastic fiber proteins and reduces collagen, leading to wrinkle formation and skin laxity [4]. Collagen reduction is caused by matrix metalloproteinase (MMP) in the dermal layers, which is activated by UV light $[5,6]$. MMPs, such as zinc-dependent peptides involved in the reconstruction of the extracellular matrix (endopeptidases), are related to skin cell death, skin ulcers, tumor invasion, and metastasis [7]. Among MMPs, MMP-1 degrades type I and type III collagen, which comprise the largest portion of the extracellular matrix. Increased expression of MMPs in the skin damaged by UV light has been shown to cause segregation, dispersion, and disorder of collagen bundles [8]. MMPs are divided into four subfamilies depending on their structural and functional properties: interstitial collagenase, stromelysin, gelatinase, and membrane-type MMP (MT-MMP) [9]. MMP-3, also known as stromelysin 1, activates proMMP-1 by degrading proteoglycan, laminin, fibronectin, gelatin, type III collagen, and type IV collagen in the basement membrane $[10,11]$. MMP-2 is a gelatinase that degrades collagen fragments 
degraded by MMP-1 and degrades type IV collagen, playing a major role in skin aging [12]. Homeostasis in MMPs produced in the body is maintained via modulation of TIMP proteins (tissue inhibitors of MMPs and TIMPs) and is regulated by the action of their proteolytic enzyme system. TIMP-1 is a general inhibitor associated with the MMP family and has various functions, including regulating cell proliferation and apoptosis and controlling angiogenesis and inflammatory response [13]. Collagen degradation by MMP activation is caused by the signal transduction pathway of the transcription factor activator protein-1 (AP-1) via the activation of the mitogen-activated protein kinase pathway by oxidative stress such as UV light $[14,15]$. Thus, suppression of the activity of MMP-1 and increase of collagen synthesis can maintain the elasticity of the skin tissue and prevent wrinkle formation and skin laxity. Recently, to reduce skin irritation caused by various synthetic substances, attention has been paid to functional cosmetic materials possessing antioxidant, anti-wrinkle, and whitening properties such as vitamin E, flavonoids, phenolic acid, and carotenoid obtained from natural plants. Pinus rigida Mill. (pitch pine), native to the eastern part of North America, is an evergreen coniferous tree belonging to the pine family. Among the coniferous trees found in Korea, P. rigida Mill. has the third largest distribution following pine and larch [16]. However, because its adhesiveness and paintability are poor, its use as timber is considered difficult. To date, various studies have been conducted to explore its increased efficient and high value-added applications [17]. Pine trees comprise leaves, pine cones, pollens, rosin, and husks, whereas pine leaves that have been most actively studied contain essential oil components such as $\alpha$-pinene, $\beta$-pinene, and camphene; flavonoids such as quercetin and kaempferol; and resins. Further, it has been reported to be effective in antioxidation and antibacterial and microorganism growth inhibition [18-20]. Pine bark contains approximately $20 \%-$ $30 \%$ phenolic compounds. Dihydroquercetin-3'-0- $\beta$-galactoside

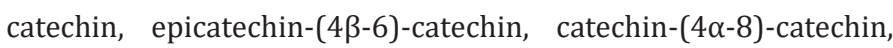

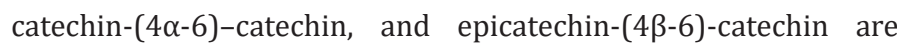
known compounds of proanthocyanidin $[21,22]$. In this study, rigida pine bark was applied to UVB-damaged human fibroblasts, and the effect of photoaging through the expression of ROS and inhibition of MMPs was examined to verify the functionality of the bark as a cosmetic material.

\section{Materials and Methods}

\section{Plant material}

The inner bark of $P$. rigida Mill. used in this experiment was collected in November 2016 from P. rigida stand in Gyeongsan City (Gyeongbuk-do) by removing the outer bark. The specimens and extracts have been stored in Skin Immunity Pharmacological Laboratory of Department of Cosmeceutical Science, Daegu Haany University.

\section{Sample Extraction}

Ethanol extract of ligand was loaded with 10-times the amount of acetone and water in a ratio of 7:3(v/v). Following 3-day extraction, the solution was filtered using a filter paper (Whatman
No. 2, Tokyo, Japan), and the obtained acetone crude extract was concentrated under reduced pressure. Then, the crude extract was suspended in water. Fraction extraction was then conducted thrice with the same amount of $\mathrm{CHCl}_{3}$, and the water layer was extracted thrice with same amount of EtOAc. As a result, EtOAc and water extracts were obtained. In this study, EtOAc extract (PRE) obtained from P. rigida Mill. was used.

\section{Cell Strain Culture and Cytotoxicity Measurement}

The human fibroblast cell line CCD-986sk used for cytotoxicity measurement was purchased from American Culture Collection (ATCC; Manassas, VA, USA). Dulbecco's modified Eagle's medium (DMEM), fetal bovine serum (FBS), penicillin/streptomycin, and $0.4 \%$ trypan blue stain were purchased from Gibco BRL Co. (Rockville, NE, USA) for cytotoxicity measurement and culture, and 3-[4,5-dimethylthiazol-2-yl]-2,5-diphenyl-tetrazoliumbromide (MTT) was purchased from Sigma Chemical Co. (St. Louis, MO, USA). Primary and secondary antibodies to MMP-1, MMP-2, MMP-3, and $\beta$-actin were procured from Santa Cruz (Santa Cruz, CA, USA). Each cell was cultured using DMEM culture medium supplemented with $10 \%$ FBS and $1 \%$ penicillin/streptomycin $(100 \mathrm{U} / \mathrm{mL})$ and subcultured in an incubator at $37^{\circ} \mathrm{C}$ and $5 \% \mathrm{CO}_{2}$.

\section{MTT Assay Cytotoxicity Measurement for Safety Evaluation}

CCD-986sk cells were uniformly dispensed in a 96-well plate $(0.18 \mathrm{~mL})$ at a density of $5 \times 10^{3}$ cells/well. PRE was prepared at concentrations of $5,10,20,40,60,80$, and $100 \mu \mathrm{g} / \mathrm{mL}$ and 0.02 $\mathrm{mL}$ of the solutions was added. Then, the cells were cultured in a $5 \% \mathrm{CO}_{2}$ incubator at $37^{\circ} \mathrm{C}$ for $24 \mathrm{~h}$. Further, $0.02 \mathrm{~mL}$ MTT solution prepared at a concentration of $5 \mathrm{mg} / \mathrm{mL}$ was added, and the solution was cultured for $4 \mathrm{~h}$. Following completion, the culture solution was removed, and $0.15 \mathrm{~mL}$ DMSO was added to each well. After incubation at room temperature for $15 \mathrm{~min}$, absorbance was measured at $540 \mathrm{~nm}$ with an ELISA reader. Cytotoxicity was measured by the absorbance reduction rate of two groups: sample solution addition group and non-addition group.

\section{Type I Procollagen Synthesis Measurement}

To measure the amount of procollagen type I synthesized when the CCD-986sk cells were treated at different concentrations by PRE, the cells were dispensed in a 24-well plate at a density of $1 \times$ $10^{4} \mathrm{cells} /$ well and then stabilized for $24 \mathrm{~h}$. Next, the cultured medium was removed, $1 \mathrm{~mL}$ PBS was added; the cells were irradiated with UVB $\left(20 \mathrm{~mJ} / \mathrm{cm}^{2}\right)$ and treated with PRE at different concentrations; and the cells were cultured for $48 \mathrm{~h}$. The supernatant from each well was then recovered and added to each well of procollagen Type I C-Peptide EIA kit (Takara-Bio Inc., Shiga, Japan), and the total amount of procollagen type I was measured according to the manufacturer's protocol.

\section{Measurement of TIMP-1 Synthesis}

After the CCD-986sk cells were cultured, the cells were inoculated in a 6-well plate at a density of $1 \times 10^{5}$ cells/well and cultured for $24 \mathrm{~h}$. Following the $24 \mathrm{~h}$ culture, the medium was 
removed and $1 \mathrm{~mL}$ PBS was added; after UVB irradiation $(20 \mathrm{~mJ} /$ $\mathrm{cm}^{2}$ ), PBS was removed. After DMEM medium not containing $10 \%$ FBS and $1 \%$ penicillin streptomycin was substituted by diluting it with 5, 10, and $20 \mu \mathrm{g} / \mathrm{mL}$ PRE, it was cultured for $48 \mathrm{~h}$. The supernatant was collected, TIMP-1 (R\&D system Inc., MN, USA) was tested according to the kit protocol, and the absorbance was measured at $450 \mathrm{~nm}$ with a microplate reader.

\section{Measurement of Protein Expression Using Western Blot}

CCD-986sk cells were uniformly dispensed in a 6-well plate at a density of $6 \times 10^{5}$ cells/well and cultured for $24 \mathrm{~h}$. Then, PRE was irradiated with UVB at a dose of $20 \mathrm{~mJ} / \mathrm{cm}^{2}$ and treated with the control, i.e., $25 \mu \mathrm{g} / \mathrm{mL}$ epigallocatechin gallate (EGCG), at concentrations of 5,10 , and $20 \mu \mathrm{g} / \mathrm{mL}$ and cultured for $48 \mathrm{~h}$. The cells were lysed with RIPA buffer (Pierce, IL, USA) and centrifuged $\left(12,000 \mathrm{rpm}, 4^{\circ} \mathrm{C}, 30 \mathrm{~min}\right)$, and the cell membrane components were then removed to obtain the supernatant. Next, proteins were quantified by Bradford assay. In total, $20 \mu \mathrm{L}$ protein was electrophoresed using $10 \%$ sodium dodecyl sulfate polyacrylamide gel electrophoresis and transferred to a PVDF membrane to inhibit nonspecific binding of the antibody. It was then transferred at a voltage of $60 \mathrm{~V}$ for more than $2 \mathrm{~h}$. After blocking with tris buffer solution containing $5 \%$ skim milk for $1 \mathrm{~h}$, the cells were reacted with primary and secondary antibodies of MMP-1, MMP-2, MMP-3, and $\beta$-actin. Next, the cells were reacted with Immobilon Western
Chemiluminescent HRP substrate (Millipore, MA, USA) for $60 \mathrm{~min}$, and the band density was confirmed using EZ-Capture MG (ATTO Corporation, Tokyo, Japan).

\section{RNA Isolation and RT-PCR for Gene Expression Analysis}

To observe the effect of UVB irradiation on the expression of the MMP-1, MMP-2, and MMP-3 genes in the fibroblasts of PRE, the CCD986sk cells were evenly dispensed in a 6-well pate at a density of $1 \times$ $10^{5} \mathrm{cells} /$ well and cultured for $48 \mathrm{~h}$. After the medium was removed, the cells were irridiated with UVB at a dose of $20 \mathrm{~mJ} / \mathrm{cm}^{2}$ and treated with PRE $(5,10$, and $20 \mu \mathrm{g} / \mathrm{mL})$, whereas the control EGCG was treated at a concentration of $25 \mu \mathrm{g} / \mathrm{mL}$ for $48 \mathrm{~h}$. Total RNA was then washed thrice with PBS and collected, and the trizol reagent was isolated using Invitrogen (Carlsbad, CA, USA). Total RNA $(2 \mu \mathrm{g})$ and PCR primer oligonucleotide were mixed with the RT-PCR mixer, and RT-PCR was performed. (Table 1) summarizes the primers used. CCD-986sk cells were lysed with lysis buffer and centrifuged at $12,000 \mathrm{rpm}$ at $4{ }^{\circ} \mathrm{C}$ for $20 \mathrm{~min}$. cDNA was prepared by incubation at $42^{\circ} \mathrm{C}$ for $1 \mathrm{~h}$ under RT conditions, and reverse transcriptase was inactivated by incubation at $94{ }^{\circ} \mathrm{C}$ for $5 \mathrm{~min}$. The subsequent PCR conditions were based on 30 cycles of denaturation at $94^{\circ} \mathrm{C}$ for $30 \mathrm{~s}$, annealing at $50{ }^{\circ} \mathrm{C}$ for $30 \mathrm{~s}$, and extension at $72{ }^{\circ} \mathrm{C}$ for $90 \mathrm{~s}$, and the optimal conditions were adjusted according to the type of target cDNA. The amplified cDNA was separated by electrophoresis using $1.2 \%$ agarose gel and confirmed by EZ-Capture MG.

Table 1: The sequences of the primers of MMP-1, MMP-2, MMP-3 and GAPDH.

\begin{tabular}{|c|c|c|}
\hline Gene & Primer & Sequence $\left(\mathbf{5}^{\prime} \rightarrow \mathbf{3}^{\prime}\right)$ \\
\hline MMP-1 & Forward & AGC GTG TGA CAG TAA GCT AA \\
\cline { 2 - 3 } MMP-1 & Reverse & GTT TTC CTC AGA AAG AGC AGC AT \\
\hline MMP-2 & Forward & TTG CCA TCC TTC TCA AAG TTG TAG G \\
\hline MMP-2 & Reverse & CAC TGT CCA CCC CTC AGA GC \\
\hline MMP-3 & Forward & TTG TTC TTT GAT GCA GTC AGC \\
\hline MMP-3 & Reverse & GAT TTG CGC CAA AAG TGC \\
\hline GAPDH & Forward & CCACCCAGTACAGCGTCAAC \\
\hline
\end{tabular}

\section{Zebrafish Breeding Condition and Embryo Acquisition}

Zebrafish (Danio rerio) was obtained from the Zebra Fish Bank of Chungnam National University and was used for the extension of the breeding period. All experimental protocols were approved and conducted according to the guidelines and regulations of the Animal Ethics Committee of Chungnam National University. Wildtype zebrafish were provided by the Zebrafish Center for Disease Modeling, Korea. The rearing condition was kept constant at 28 ${ }^{\circ} \mathrm{C} \pm 1{ }^{\circ} \mathrm{C}$ with a 16 -h/8-h light/dark cycle (Rotifer continuous culture system, GDBC, Korea). They were fed brine shrimp (Ocean Star International, Utah, USA). Female and male fish with at least five spawning experiences were fed adequate feed the day prior to spawning; $24 \mathrm{~h}$ later, irradiation of light was used to produce embryos. The produced embryos were incubated in an incubator at $28^{\circ} \mathrm{C} \pm 1{ }^{\circ} \mathrm{C}$ for 2 days in pre-manufactured Egg water (Sea salt solution, Aquarium systems, France) to avoid exceeding a maximum of 50 eggs in a 100-mm petri dish, and the Egg water was replaced periodically and used in the experiment.

\section{Oxidative Damage Induction Using}

UVB Spawned zebrafish embryos were dispensed into each 60-mm petri dish (5 embryos/dish), followed by 2-day culturing in an incubator (TempMini H2200-H, China) to obtain young fish. PRE was dissolved in the Egg water at concentrations of 5, 10, and $20 \mu \mathrm{g} / \mathrm{mL}$ and treated with $5 \mathrm{ml}$ of each solution. The negative control group Egg water was treated with $5 \mathrm{ml}$ of each solution. After pretreatment of the sample, the sample was washed with the Egg water and irradiated for $1 \mathrm{~min}$ at a dose of $50 \mathrm{~mJ} / \mathrm{cm}^{2} \mathrm{UVB}$ using a UV irradiator (UV-X000, LAB24, Korea). After UVB irradiation, 2',7'- dichlorofluorescein diacetate (DCFH-DA, Sigma-Aldrich, USA) was applied and the solution was incubated for $1 \mathrm{~h}$ in an incubator. Later, the zebrafish larvae were washed with the Egg water and observed with a glaucoma microscope (Dino-Lite, Taipei). 


\section{Statistical Analysis}

Statistical analysis was performed using SPSS 10.0, and significant differences were verified at statistical significance level of $\mathrm{p}<0.05,0.01$ using t-test using ANOVA (Analysis of Variance) program.

\section{Results and Discussion \\ Cell Viability of PRE in UVB-Stimulated Fibroblasts}

To ensure the synthesis of type I procollagen and expression of MMPs in the fibroblasts of PRE, cytotoxicity was first examined. The cells treated with PRE at concentrations of 5, 10, 20, 40, 60, 80, and $100 \mu \mathrm{g} / \mathrm{mL}$ showed cell viability of above $90 \%$ at concentrations below $20 \mu \mathrm{g} / \mathrm{mL}$. It was considered that there was no toxicity, and the experiment was conducted at a concentration of $20 \mu \mathrm{g} / \mathrm{mL}$ or less (Figure 1).

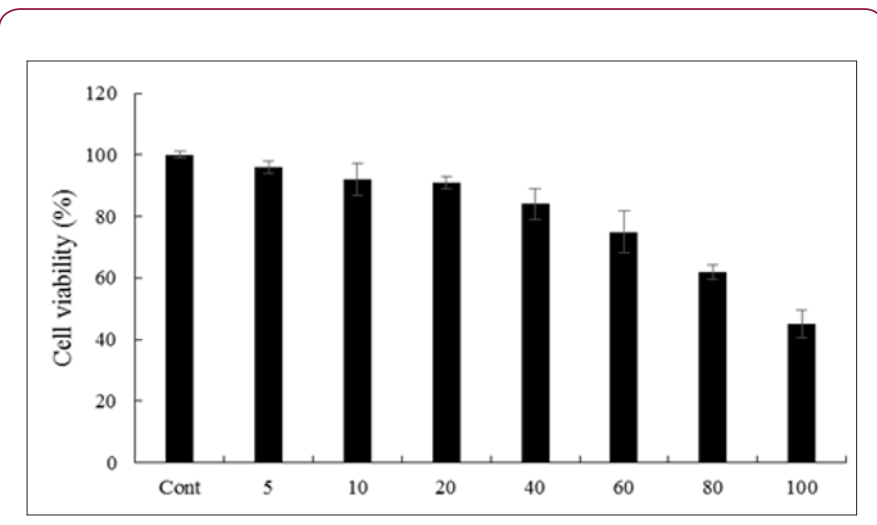

Figure 1: Cell viability of PRE on CCD-986sk human fibroblast cells by MTT assay. The cells were treated various concentrations of sample. The results were expressed as the average of triplicate.

\section{PRE Type I Procollagen and TIMP-1 Expression Rates}

The dermis of the skin occupies most of the complete skin surface and reflects the characteristics of the skin such as flexibility, elasticity, and tension. The biosynthesis and degradation of the dermal collagen are important in skin aging and skin regeneration processes in wound healing [23]. Collagen, which accounts for $90 \%$ of the dermis, is divided into collagen types I-V and is synthesized as a procollagen precursor in the cell; then, it is secreted out of the cell and polymerized into collagen fiber [24]. Approximately, $80 \%$ of the collagen is type I collagen and is downregulated by UV light, and protein MMPs are involved in its degradation [25]. Procollagen is a precursor of collagen and has a peptide sequence called a propeptide. Propeptide is involved in collagen formation in the endoplasmic reticulum; therefore, the amount of collagen biosynthesis can be estimated by measuring the amount of propeptide to antagonize the effect of biosynthesis [26]. The results of the estimation of the amount of procollagen biosynthesis of PRE are shown in (Figure 2A). The control had an expression level of $100.0 \% \pm 4.5 \%$ and the group irradiated with UVB $\left(20 \mathrm{~mJ} / \mathrm{cm}^{2}\right)$ of $38 \% \pm 2.9 \%$; the levels noted for $10 \mathrm{ppm}$ PRE, 20ppm PRE, and EGCG were $48 \% \pm 2.8 \%, 59 \% \pm 1.9 \%$, and $72 \% \pm 3.5 \%$, respectively.

Thus, it was confirmed that the expression level of procollagen increased by the addition PRE in a concentration-dependent manner. The action of MMPs that degrade collagen is regulated by inhibitors such as 2-macroglobulin or TIMP-1 [27,28], which are secreted to maintain cellular homeostasis. To date, four types of TIMP have been identified, and TIMP inhibits the function of MMP by forming strong non-covalent bonds with inactivated MMP at a ratio of 1:1 [29]. According to (Figure 2B), the control had an expression level of $100.0 \% \pm 1.9 \%$, whereas the irradiated group had a level of $43 \% \pm 1.1 \%$; the levels noted for $10 \mathrm{ppm}$ PRE, $20 \mathrm{ppm}$ PRE, and EGCG were $49 \% \pm 2.3 \%, 51 \pm 2.7 \%$, and $62 \pm 3.5 \%$. Thus, it was confirmed that PRE increased the expression level of TIMP-1.

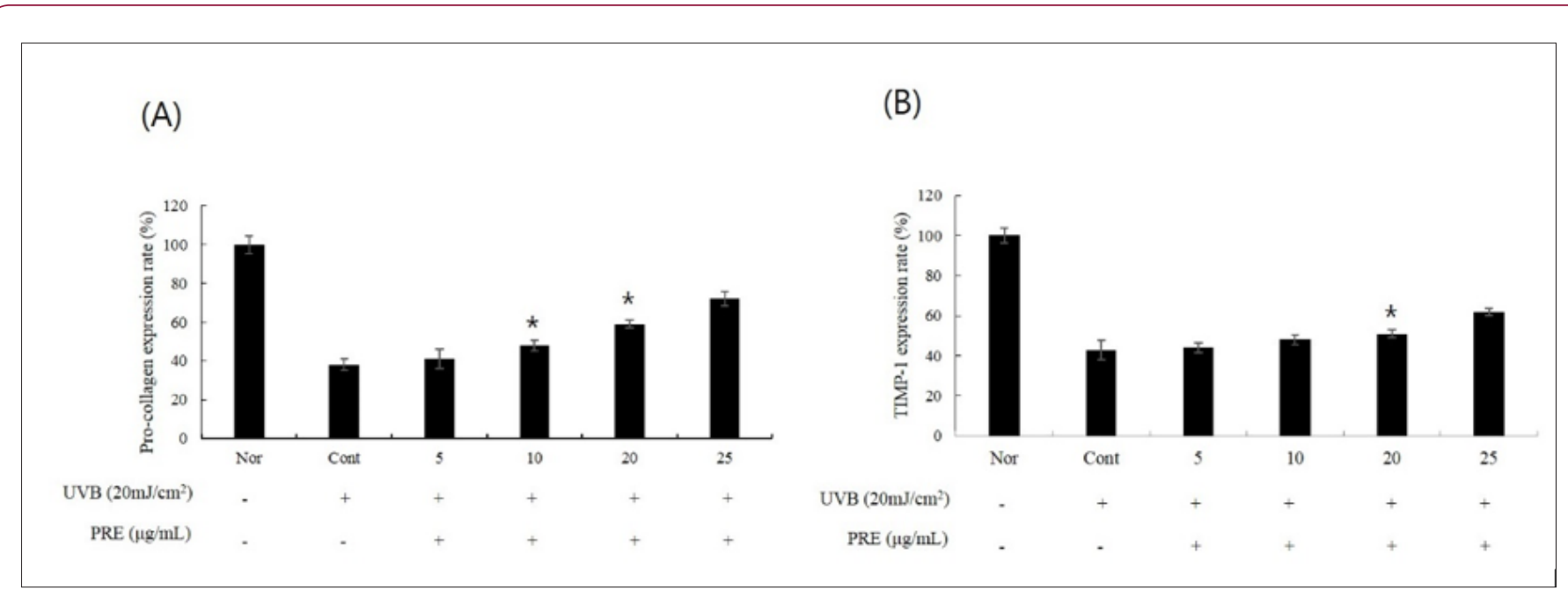

Figure 2: Effect of PRE in the expression of procollagen (A) and TIMP-1 (B) in the UVB-induced CCD-986sk human fibroblast cells. Cells were treated for $48 \mathrm{~h}$ with PRE $(5,10,20 \mu \mathrm{g} / \mathrm{mL})$ during UVB $\left(20 \mathrm{~mJ} / \mathrm{cm}^{2}\right)$ activation. The results were expressed as the average of triplicate. ${ }^{*} \mathrm{p}<0.05,{ }^{* *} \mathrm{p}<0.01$ compared with control. 


\section{Protein synthesis and mRNA expression measurement of MMP-1, -2 , and -3}

MMPs are enzymes that degrade the extracellular matrix and are induced by AP-1 activated by UV light; they are secreted by many cells including human keratinocytes and fibroblasts, and their expression increases after UV irradiation in the normal epidermis [10]. Among MMPs, MMP-1 is known as collagenase 1 and involves type I and III collagen as substrates; MMP-2 is known as gelatinase and degrades type IV and type VII collagen; and MMP-3, also known as stromelysin 1, degrades laminin (an adhesive protein in the basement membrane) and breaks down type IV collagen, producing pro-MMP-1 (a zymogen) [11]. Reduction of total collagen production in the extracellular matrix of the skin following UV irradiation reduces elasticity in photoaged skin and causes skin laxity [30]. Therefore, various plant-derived natural materials capable of reducing the production of MMPs and increasing procollagen production can reduce photoaging. Western blot analysis was conducted to determine the effect of PRE extracts on MMP-1, -2, and -3 expressions by UVB irradiation of fibroblasts. The results are shown in (Figure 3 ). It was confirmed that as the concentration of PRE extract increased, MMP-1 decreased significantly compared with the untreated group.

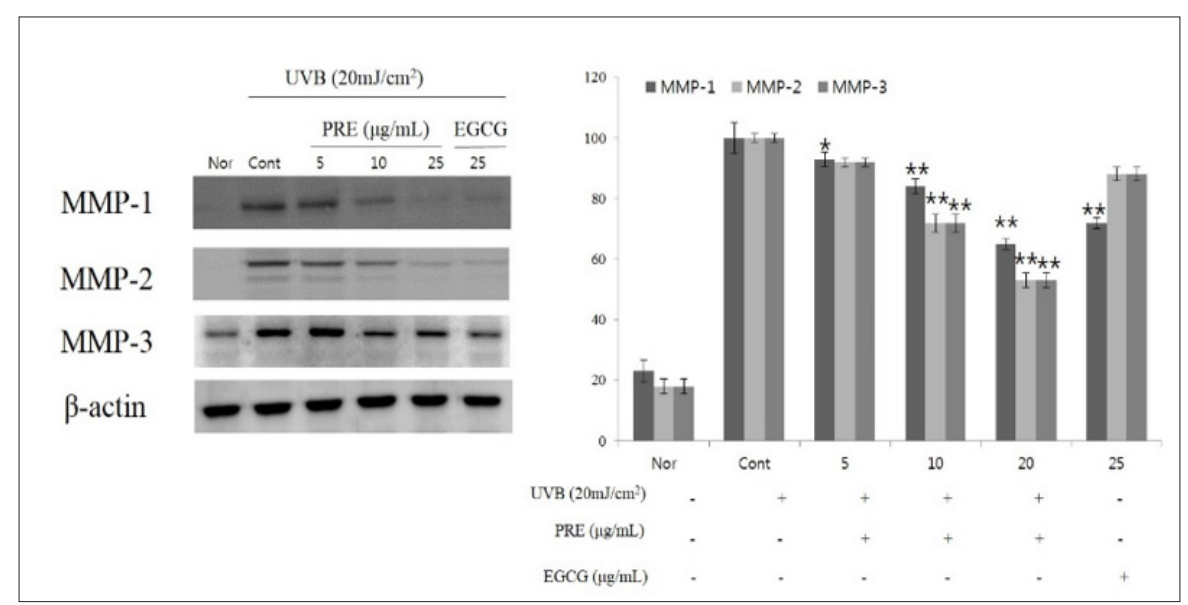

Figure 3: Expressions of MMP-1, -2 and MMP-3 evaluated by protein level in CCD-986sk fibroblasts after PRE treatment. CCD-

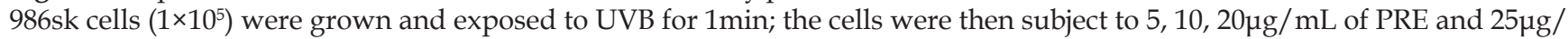
$\mathrm{mL}$ of EGCG treatment. The protein levels were normalized using EZ-Capture MG. The results were expressed as the average of triplicate. ${ }^{*} \mathrm{p}<0.05,{ }^{* *} \mathrm{p}<0.01$ compared with control.

The expression level of MMP-1 was found to be $16 \% \pm 2.5 \%$ and $35 \% \pm 1.9 \%$ for 10 and $20 \mu \mathrm{g} / \mathrm{mL}$ PRE, respectively, and $28 \% \pm 1.8 \%$ for $25 \mu \mathrm{g} / \mathrm{mL}$ EGCG. The expression level of MMP-2 was $31 \% \pm 2.9 \%$ and $58 \% \pm 2.4 \%$ for 10 and $20 \mu \mathrm{g} / \mathrm{mL}$ PRE, respectively, and $58 \% \pm$ $2.2 \%$ for $25 \mu \mathrm{g} / \mathrm{mL}$ EGCG. The expression level of MMP-3 was $50 \%$ $\pm 2.9 \%$ and $49 \% \pm 2.4 \%$ for 10 and $20 \mu \mathrm{g} / \mathrm{mL}$ PRE, respectively, and $58 \% \pm 2.2 \%$ for $25 \mu \mathrm{g} / \mathrm{mL}$ EGCG, highlighting its efficacy as a MMPS inhibitor. RT-PCR was performed to observe the expression of mRNA according to the treatment with PRE extract, and the re- sult of the measurement based on the expression of GAPDH as a housekeeping gene is shown in (Figure 4). The expression levels of MMPs increased in the UVB-irradiated groups. As PRE concentration increased, MMP-1 showed a significant reduction of more than $50 \%$ for 10 and $20 \mu \mathrm{g} / \mathrm{mL}$ PRE and MMP-2 decreased in a concentration-dependent manner. Therefore, PRE is believed to promote the expression of TIMP-1 in fibroblasts damaged by photoaging and to reduce the degradation of extracellular matrix proteins by active MMPs, resulting in the suppression of wrinkle formation.

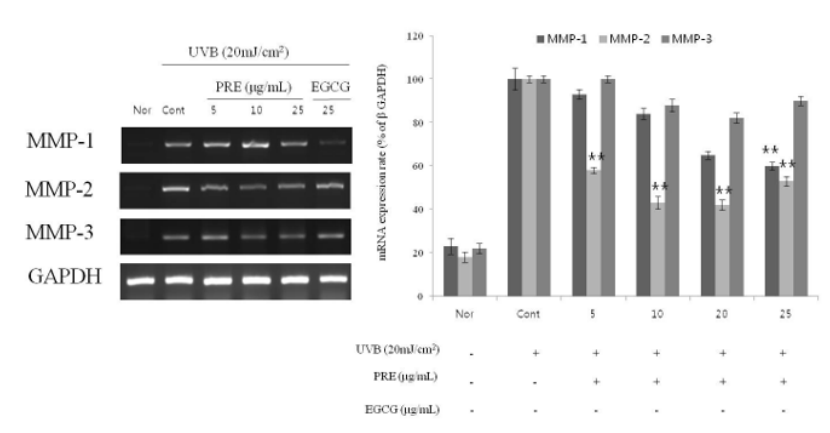

Figure 4: Expressions of MMP-1, -2 and MMP-3 evaluated by mRNA level in CCD-986sk fibroblasts after PRE treatment. CCD-986sk cells $\left(1 \times 10^{5}\right)$ were grown and exposed to UVB for $1 \mathrm{~min}$; the cells were then subject to $5,10,20 \mu \mathrm{g} / \mathrm{mL}$ of PRE and $25 \mu \mathrm{g} / \mathrm{mL}$ of EGCG. The mRNA levels were normalized using EZ-Capture MG. The results were expressed as the average of triplicate. ${ }^{*} \mathrm{p}<0.05,{ }^{* *} \mathrm{p}<0.01$ compared with control 


\section{Protective Effect of PRE in Zebrafish that Induced ROS} with UVB

Zebrafish is readily available as a vertebrate with humanlike genetic information and organ systems and exhibits a short interval between generations (Figure 5). Further, because zebrafish embryos remain transparent for several days following birth, their organs can be observed. Thus, it has recently been used as an animal model for various human diseases [31]. ROS measurement of UVBinduced zebrafish employs the property that DCFH-DA reacts with
ROS in the form of DCFH, which is liberated from the acetyl group, to produce a fluorescent material [32]. After pretreatment of PRE extracts at concentrations of 5,10 , and $20 \mu \mathrm{g} / \mathrm{mL}$, the ROS levels in the zebrafish embryos induced by UVB damage were examined based on fluorescence intensity. As a result, it was confirmed that the fluorescence intensity decreased in a concentration-dependent manner compared with the positive control group only irradiated with UVB. In particular, the ROS level in the group treated with $20 \mu \mathrm{g} / \mathrm{mL}$ PRE reduced by $19.6 \%$ compared with the level observed in the positive control group.

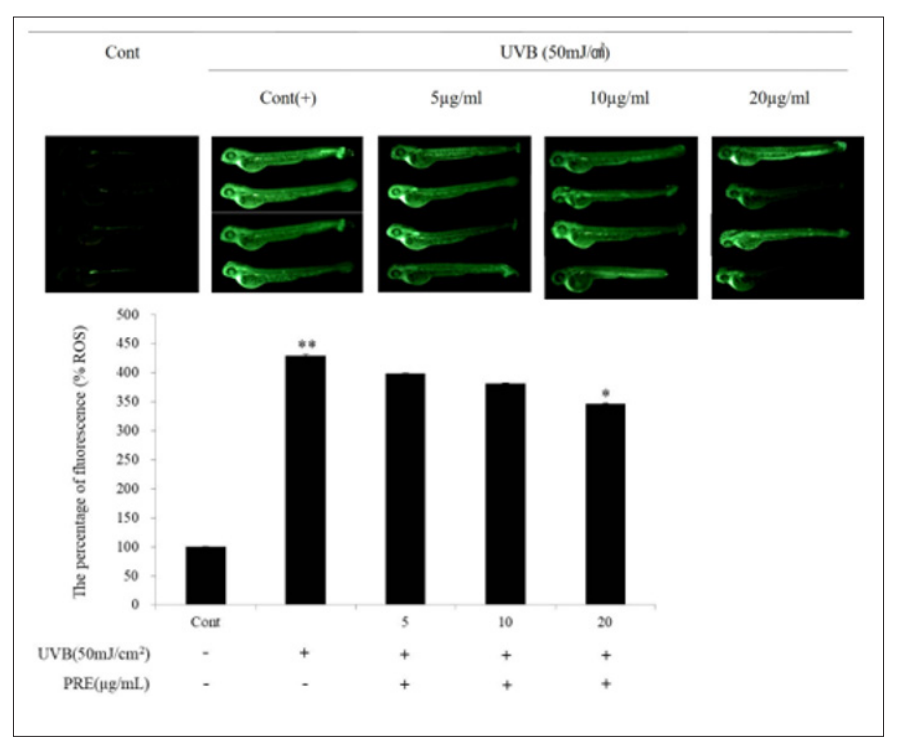

Figure 5: Protective effect of PRE against UVB-induced ROS generation in zebrafish. Zebrafish embryo were exposed to UVB $\left(50 \mathrm{~mJ} / \mathrm{cm}^{2}\right)$ and treated with various concentrations $(5,10,20 \mu \mathrm{g} / \mathrm{mL})$. After incubation, zebrafish embryos were stained with DCFH-DA and intracellular ROS were detected by fluorescence microscopy. The results were expressed as the average of triplicate. ${ }^{*} \mathrm{p}<0.05,{ }^{* *} \mathrm{p}<0.01$ compared with control. The results were expressed as the average of triplicate. ${ }^{*} \mathrm{p}<0.05$, ${ }^{* *} \mathrm{p}<0.01$ compared with control.

\section{Acknowledgments}

This work was supported by the Technology Innovation Program "Global Beauty Care business model and product development through local bases and infrastructure development in Southeast Asia" ('No.10070303') funded by the Ministry of Trade, Industry \& Energy (MOTIE, Korea).

\section{References}

1. Lee JH, Park KR, Nho YC, Son TI (2003) Preparation and characterization of hydrogels by radiation. J Chitin Chitosan 8: 10-17.

2. Chung JH (2003) Photoaging in Asians. Photodermatol Photoimmunol Photomed 19(3): 109-121.

3. Durai PC, Thappa DM, Kumari R, Malathi M (2012) Aging in elderly: chronological versus photoaging. Indian J Dermatol 57(5): 343-352.

4. Fisher GJ, Kang S, Varani J, Bata Csorgo Z, Wan Y, et al. (2002) Mechanisms of photoaging and chronological skin aging. Arch Dermatol 138(11): 1462-1470.

5. Chung JH, Seo JY, Choi HR, Lee MK, Youn CS, et al. (2001) Modulation of skin collagen metabolism in aged and photoaged human skin in vivo. J Invest Dermatol 117(5): 1218-1224.

6. Gilchrest BA (1996) A review of skin ageing and its medical therapy. Br J Dermatol 135(6): 867-875.
7. Birkedal Hansen $H$ (1995) Proteolytic remodeling of extracellular matrix. Curr Opin Cell Biol 7(5): 728-735.

8. Choi MS, Yoo MS, Son DJ, Jung HY, Lee SH, et al. (2007) Increase of collagen synthesis by obovatol through stimulation of the TGF-beta signaling and inhibition of matrix metalloproteinase in UVB-irradiated human fibroblast. J Dermatol Sci 46(2): 127-137.

9. Fisher GJ, Kang SW, Voorhees JJ, H S Talwar, J Lin, et al. (1998) Retinoic acid inhibits induction of c-Jun protein by ultraviolet radiation that occurs subsequent to activation of mitogen-activated protein kinase pathways in human skin in vivo. J Clin Invest 101(6): 1432-1440.

10. Lee YR, Noh EM, Han JH, Kim JM, Hwang JK, et al. (2012) Brazilin inhibits UVB-induced MMP-1/3 expressions and secretions by suppressing the NF- $\kappa B$ pathway in human dermal fibroblasts. Eur J Pharmacol 674(2-3): 80-86.

11. Oh JH, Kim A, Park JM, Kim SH, Chung AS (2006) Ultraviolet B-induced matrix metalloproteinase- 1 and -3 secretions are mediated via PTEN/ Akt pathway in human dermal fibroblasts. J Cell Physiol 209: 775-785.

12. Lim SC (2001) Expression of matrix metalloproteinases and its inhibitor in gastric adenocarcinoma. Cancer Res Treat 33(3): 199-206.

13. Alexander CM, Howard EW, Bissell MJ, Werb Z (1996) Rescue of mammary epithelial cell apoptosis and entactin degradation by a tissue inhibitor of metalloproteinases-1 transgene. J Cell Biol 135(6): 16691677. 
14. Moon HJ, Lee SR, Shim SN, Jeong SH, Stonik VA, et al. (2008) Fucoidan inhibits UVB-induced MMP-1 expression in human skin fibroblasts. Biol Pharm Bull 31(2): 284-289.

15. Rittié L, Fisher GJ (2002) UV-light-induced signal cascades and skin aging. Ageing Res Rev 1(4):705-720.

16. Kwon KC, Lee DK (2006) Biomass and energy content of Pinus rigida stand in Gwangju, Gyeonggi Province. Jour Korean For Ener 25: 39-45.

17. Seo JW, Lee ES, Kang CY, Kim SB, Yoon YH, et al. (2015) Comparison of quality characteristics of woodpellet manufactured from Pinus densiflora S. et Z. and Pinus rigida Mill. J Korean Wood Sci Technol 43(3): 374-380.

18. Koukos PK, Papadopoulou KI, Patiaka DT, Papagiannopoulos AD (2000) Chemical composition of essential oils from needles and twigs of balkan pine (Pinus peuce Grisebach) grown in Northern Greece. J Agric Food Chem 48(4): 1266-1268.

19. Lim YS, Bae MJ, Lee SH (2002) Antimicrobial effects of Pinus densiflora Sieb. et Zucc. ethanol extract on Listeria monocytogenes. J Kor Soc Food Sci Nutr 31: 333-337.

20. Zeng WC, Zhang Z, Gao H, Jia LR, He Q (2012) Chemicalcomposition, antioxidant, and antimicrobial activities of essential oil from pine needle (Cedrus deodara). J Food Sci 77(7): 824-829.

21. Song HK, Oh SJ (1996) Isolation and structure elucidation of proanthocyanidin in bark of Pinus densiflora. J Korean Wood Sci Technol 24: 81-93.

22. Kim H, Song HK, Chung DK (1991) Chemical analysis of Coniferous Flavonoids in Korea - The flavonoids of Red Pine Bark (Pinus densiflora). J Korean Wood Sci Technol 19(4): 73-79.

23. Wulf HC, Sandby Møller J, Kobayasi T, Gniadecki R (2004) Skin aging and natural photoprotection. Micron 35(3): 185-191.

\section{ISSN: 2574-1241}

DOI: 10.26717/BJSTR.2019.12.002285

Jin Tae Lee. Biomed J Sci \& Tech Res

CC (i) This work is licensed under Creative

Submission Link: https://biomedres.us/submit-manuscript.php
24. Fisher GJ, Wang ZQ, Datta SC, Varani J, Kang S, et al. (1997) Pathophysiology of premature skin aging induced by ultraviolet light. N Engl J Med 337: 1419-1429.

25. Davis GE, Saunders WB (2006) Molecular balance of capillary tube formation versus regression in wound repair: role of matrix metalloproteinases and their inhibitors. J Investig Dermatol Symp Proc 11(1): 44-56.

26. Dumont SL, Cattuzzato G, Trouvé N Chevrot, C Stoltz (2010) Two new lipoaminaocids with complementary modes of action: new prospects to fight out against skin aging. Int J Cosmet Sci 32(1): 9-27.

27. Enjoji M, Kotoh K, Iwamoto H, Nakamuta M, Nawata H (2000) Selfregulation of Type?collagen degradation by collagen-induced production of matrix metalloproteinase-1 on cholangiocarcinoma and hepatocellular carcinoma cells. In vitro Cell Dev Biol Anim 36: 71-73.

28. Fisher GJ, Voorhees JJ, Talwar HS, Lin J (1999) Molecular mechanism of photoaging in human skin in vivo and their prevention by all-trans retinoic acid. Photochem Photobiol 69(2): 154-157.

29. Stetler Stevenson WG (1990) Type IV collagenases in tumor invasion and metastasis. Canser Metastsis Rev 9(4): 289-303.

30. Lee KE, Mun S, Pyun HB, Kim MS, Hwang JK (2012) Effects of macelignan isolated from Myristica fragrans (Nutmeg) on expression of matrix metalloproteinase-1 and type I procollagen in UVB-irradiated human skin fibroblasts. Biol Pharm Bull 35(10): 1669-1675.

31. Detrich HW (1999) Overview of the zebrafish system. In Detrich HW, Westerfield M, Zon LI (Eds.) The zebrafish: biology in methods in cell biology, (1 ${ }^{\text {st }}$ Edn.) Academic Press, San Diego, USA, pp. 5-9.

32. Kim TY, Bak JP (2015) Antioxidant and protective effects of GagamDangquienmja on ultraviolet B-induced damage in human keratinocyte. J Physiol \& Pathol Korean Med 29: 457-484.

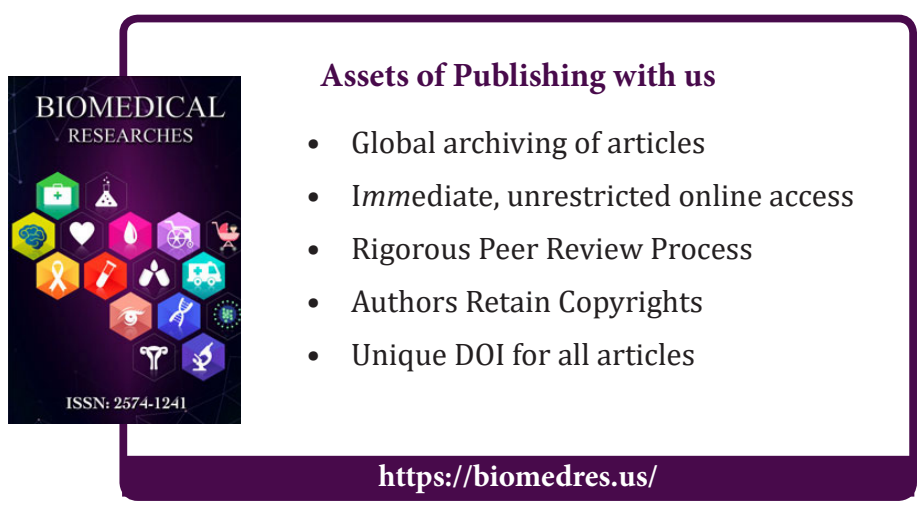

Cite this article: Young Ah J, Bo Ae K, Jin Tae L. Antioxidative and Anti-Aging Effects of Pinus Rigida Mill. Ethyl Acetate Extract on the Human Dermal Fibroblast Cell Line CCD-986sk Damaged by Ultraviolet B Radiation. Biomed J Sci \& Tech Res 12(4)-2019. BJSTR. MS.ID.002285. DOI: 